Portland State University

PDXScholar

\title{
Shifting Advertising Agency Structure and Evolving Technology
}

Sarah A. Norris

Portland State University

Follow this and additional works at: https://pdxscholar.library.pdx.edu/honorstheses Let us know how access to this document benefits you.

\section{Recommended Citation}

Norris, Sarah A., "Shifting Advertising Agency Structure and Evolving Technology" (2017). University Honors Theses. Paper 403.

https://doi.org/10.15760/honors.399

This Thesis is brought to you for free and open access. It has been accepted for inclusion in University Honors Theses by an authorized administrator of PDXScholar. Please contact us if we can make this document more accessible: pdxscholar@pdx.edu. 
Shifting Advertising Agency Structure and Evolving Technology

By

Sarah Norris

Portland State University

Honors Thesis

April-June 2017 
Table of Contents:

Abstract:....................................................................

How I Plan to do my Research:.................................................

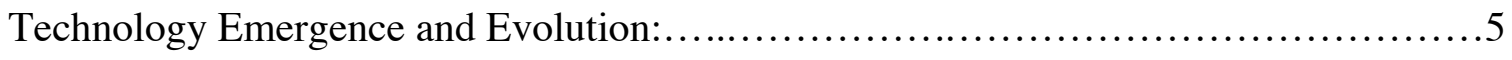

Small and Micro Businesses are Changing:.......................................

Evolving Business as Usual in Advertising:....................................... 8

Rate at Which Technology has Increased:.........................................11

The Move Away from "Traditional” Advertising Agencies:.............................12

Can Traditional Firms Make the Switch to Digital? :.................................15

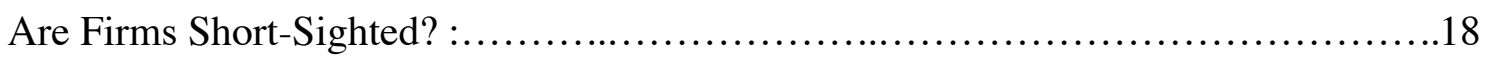

The Price Structures of Traditional Advertising Firms:...............................20

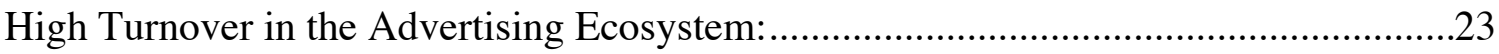

Agencies Don't Know if They Matter Any More:....................................27

What Metrics are There and How Reliable are they?:................................2 28

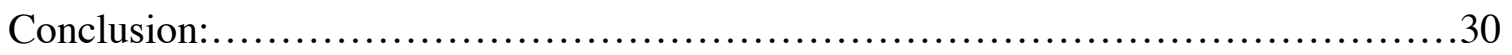




\section{Abstract}

As a senior at Portland State University I have been exposed to many real-life advertising situations. This immersion in the advertising world has been an invaluable experience that has given me significant insight into advertising agencies and their operations from multiple different positions throughout the typical firm. This experience has helped me shape my thesis into a question that is relevant not only for the advertising community as a whole but also as someone hoping to enter the field within the next few years.

My goal for this thesis is not to simply gain total knowledge in one specific area of advertising, but to create an accurate perspective of the advertising ecosystem and all the businesses and people that interact with or depend on it, as it exists today. I will go in depth on all the aspects of the "advertising ecosystem" later in this paper,) I am using this terminology as an overarching term for all businesses that rely or drive any form of work related to advertising). These businesses can range from the advertising firm itself to the catering business that supplies sandwiches for a Nike photo-shoot. As a soon-to-be college graduate, it's important to know exactly what the climate is for any potential field of work.

I came to my topic by researching trends in the advertising ecosystem that have come about with the increased use of the Internet and technology in business. Almost everyone can not only advertise for themselves, but can also have access to a multitude of analytic tools that would previously have only been available to advertising and marketing professionals. There are a growing number of firms who use social media and low-cost creative departments, and whose success now threatens the larger advertising 
agencies. Because only a relatively few brands and companies have the funds to access larger more traditional firms, more small and micro businesses are turning to the only alternatives most of them can afford. For clarification, the traditional advertising firm is an all in-house firm that deals with every aspect of the advertising process from the PR to coupon development and media buying. These traditional firms are priced in one of three ways that I will explain further in my thesis. These firms tend to be more costly than most brands can afford.

As I will discuss in my thesis the growing importance of small advertising firms has had reverberating effects on not only the industry but also the employees of the firms in question. Technology and the evolving tools of the Internet have allowed many brands and companies to reconsider the need for the traditional advertising agency, and has allowed for the growth of more non-traditional advertising shops.

\section{How I Plan to Conduct My Research}

I plan to conduct my research via a literature review of current and recently published articles reporting on new trends in advertising. The sources I will be accessing most frequently will be Ad Age, Adweek, Huffington Post, and The New York Times. These sources offer a diverse range of opinions on the advertising ecosystem, while being reliable and current, keeping up with trends as fast as they happen.

I will also be using more scholarly articles in order to assess how previous trends in advertising have affected the advertising ecosystem, and what, if any, lasting effects they have had.

One reason for choosing Ad Age and Adweek as two of my primary sources is that most articles are written from the perspective of someone inside the world of 
advertising; most people who write for these publications are veterans in the industry who offer a unique view on how advertising agencies really run. These writers have experienced almost every conceivable part of the advertising world, giving a full view of opinions on the future of the industry.

When my research is complete, it will show a full understanding of the advertising ecosystem. I will not be making a decision about whether these businesses are sustainable or viable; instead, I hope to consolidate enough information so that this paper can be used as a launching point for further research. I hope to create a working list of more current articles that fully paint a picture of where advertising is heading over the next few years.

\section{Technology Emergence and Evolution:}

For this paper, I will focus on technology relevant to the consumers of advertising and people involved in the advertising ecosystem. The technologies I will examine include social media, smartphones (which increase the amount of people who have access to the internet at all times), and "apps" that allow for easier web browsing and customized ways to interact with brands. With this narrow topic I am hoping to conduct a more focused literature review of technology in advertising in the past five years.

With $81 \%$ of Americans on social media platforms, it is sensible for advertising firms and small businesses to use these tools to host content-rich and exciting advertisements for small businesses. However, when 550 businesses with less than 100 employees were interviewed, only $3 \%$ of their advertising spending went toward online advertising, while larger ad firms spent closer to $16 \%$ (McMains, 2013). These percentages do not include having a basic website, as this has become ubiquitous with 
any business as a necessary part of the consumers process and is vital in order to foster a community among consumers, or bidirectional consumer communication.

One benefit of online advertising is that it gives businesses and advertisers easily readable metrics, such as impressions or click through rate. I will go into what these metrics mean-and how reliable they actually are-later on in this paper. Online advertising allows advertisers to see how their ad is performing in real time. These metrics also give businesses valuable insight into their consumers shopping habits. For example, when searching for a product, $57 \%$ of consumers say that an online search is their first method of research while $20 \%$ use apps to find deals and packages online as their first research method (Morrison, 2014). And 52\% of consumers say that they use some sort of coupon app to shop at least once a month (ibid.).

One major result of the use of social media is the emergence of the "microinfluencer," a term that describes someone on social media with anywhere from 500 to 10,000 followers, (the exact number is flexible). These micro-influencers have become a key component of the advertising ecosystem. The number that is important is that these micro-influencers have up to double the engagement rate as larger online celebrities, who sometimes have only $4 \%$ engagement. Currently, these micro-influencers can be a drain on resources due to the time spent finding, curating, and managing them, but with their rise in popularity firms are popping up that specialize in managing these microinfluencers (Adweek Guest, 2016). These micro-influencers solve one of the age-old dilemmas of advertising and specifically online advertising; they have a much higher perceived authenticity form their followers, they are seen as more of a peer than an advertiser, and when a company has enough of them they can have a very large 
distribution (Sammis, 2017). This section highlights how the growth in the use and continued evolution of technology in the ways that people communicate has driven the need for new services and systems. This evolution of technology and the changing way people use it has affected every step in the advertising ecosystem because it has started to change the way people communicate, share and seek information.

\section{Small and Micro Businesses are Changing:}

When talking about a small business I am going to use these definitions for my own research: a small business is any company with fewer than 500 employees and a micro business is any with fewer than 5 . These are the commonly used definitions for these terms but I wanted to clarify that these are the parameters I have set for my thesis.

Small businesses account for $54 \%$ of all transactions in the United States and the number of small businesses has increased 49\% since 1982 (Small Business Trends, 2017). $80 \%$ of all small businesses are on some form of free social media platform including Facebook, Twitter, or Pinterest; and 53\% of small businesses use it as one of their main channels of communication and engagement with their customers (Bennett, 2013). This has made communication between brands and consumers easier and faster for both the business owner and potential consumers. This increase in the number of small businesses can be partly attributed to the rise in mobile technology. Smartphone and tablet technology saves the U.S. business market a collective 2 billion hours per year and an estimated $\$ 65$ billion dollars, and the number of small businesses that use some form of mobile technology has reached 94\%, up from $85 \%$ last year (Hendricks, 2014). Small businesses utilize mobile technology not only for marketing and engagement, but POS/ Credit card processing for transaction, GPS technology for deliveries and time saving, 
and the cloud has allowed for seamless sharing among multiple franchises and business partners (Hendricks, 2014).

According to Forbes, in 2016 businesses with fewer than 50 employees were responsible for creating a total of 95,000 jobs across the U.S., and businesses with fewer than 500 employees also had notable gains in size. Small businesses account for nearly two thirds of all new jobs created since the early nineties and they provide up to half of private sector employment (Biery, 2016). Small business has driven a need for a “different" type of advertising or communication service.

\section{Evolving Advertising "Business as Usual"}

For the purpose of my thesis, I will be focused mostly on how clients interact with an agency and how an agency treats its employees. What I am hoping to uncover is how agencies have changed and how this change affects the people in the advertising world, both agency side and client side.

As more businesses are being founded one commonality among them is that employees are expected to be able to not only multi-task but constantly be improving on their skills and staying competitive even after the job is theirs. There have always been consolidations and cuts backs in the advertising ecosystem, business has always cycled back and forth between small-specialized advertising firms and big conglomerates. What we don't know is if this new wave of consolidations is different due to the new technology that most businesses now have access to. Wieden and Kennedy, which cut back hundreds of employees after the Kraft and Heinz merger, has a promised \$1.5 billion in savings in comparison to the year before the merger, most of which is estimated to come from cutting employees and consolidating positions (O’Leary, 2015). This 
should serve as a warning sign for the advertising ecosystem that a major player has shifted away from the traditional advertising firm; we have yet to see if this move was effective. One major way that advertising has evolved is that $85 \%$ of all online advertising is spent at either Facebook or Google (Heine \& Swant, 2016). Many millennials value ethical behavior very highly and many brands are beginning to distance themselves from sites with so much bad publicity and inauthentic reputations like "fake news" (Heine \& Swant, 2016). Media placement and how your message is delivered, and through what channel, has never been such a hot topic in the world of advertising, causing many creative professionals in agencies, such as copywriters or graphic designers, to wear two hats: creative and media expert. This means that business is changing again due to the impact of the Internet and different communication technologies; what we don't know is if this change is going to have a lasting effect on the advertising ecosystem.

Agencies are not only changing around people on their own. Young people who join these firms are also helping to shape and change the structure of many agencies, a common trend is a shift towards more tech savvy tactics to please clients who are seemingly only able to reach their target audience through the internet and social media. Millennials currently make up $44 \%$ percent of the advertising workforce, up from $36 \%$ percent only six years ago (Gianatasio, 2015).

From 1950 to even as late as the early 2000's the advertising process was very linear; you did research, created a plan and executed the plan. Traditional adverting firms had one main tool using paid media, and that was the one to many tools, sending their advertisement out and hoping for a return. Today's advertisers are striving to reach 
something closer to a one-to-one advertisement, where one very targeted ad reaches one consumer that the ad is tailored to.

However, with constant access to ever-changing information the advertising process has started to look more like a bi-directional or multi-directional communication loop, and the millennial's themselves are the disrupters in the industry. Gianatasio uses the term "liquid talent," stating “...young 20 and 30-somethings expand their skill sets across various disciplines and geographies. Shops have begun allowing staffers to move among departments." (Gianatasio, 2015). Heads of agencies no longer only seek out the most experienced expert in a field to hire, they are looking for people called "personality rock stars" who can multi-task and become proficient in many fields but not necessarily an expert in ant single one, but always with the goal of staying relevant and keeping new young blood flowing through the agency (Farley, 2016).

In order to stay relevant in the digital age many brands and firms now offer what is referred to as " a Cheesecake factory-size menu of ways to get stuff done". With so much consolidation happening in the advertising world, brands and firms now have to offer things that were not previously required (Roper, 2016).

Tim Roper, creative director at F. Yeah Associates, has stated that the only way people in advertising will continue to survive is if they adopt the "hyphen mentality". No employee is one role; everyone has to have his or her fingers in all the pots, not unlike the liquid talent notion discussed earlier. When you add a hyphen to your title you are eliminating a line from the budget, which is just another aspect of the consolidation happening in firms and ad-tech agencies (Roper, 2016). 


\section{Rate at Which Technology has Increased}

The technologies that I am focusing on are the three that I discussed in earlier sections: mobile phones and tablet technology, social media, and app technology and development.

Social media, with Facebook being the most well known, has grown at a significant rate. Facebook grew from one million users to one billion registered users in less than a decade, with Mark Zuckerberg stating that reaching five billion registered users is personal goal of his. Facebook has also pledged to connect five billion more people. This rapid growth will not only provide access to internet across the world but will also increase advertising opportunities for brands like Google, and will increase the need for different internet supporting services. It is estimated that $72 \%$ of all Internet users are using at least one form of social media, with Facebook leading that charge (Morrison, 2014).

Accoding to a survey of 5,000 businesses throughout America, 70\% planned to increase their budget for social media advertising from the years 2014 to 2015 , a huge testament to the power, (or at least perceived power) of social media advertising. I have included a few statistics put out by Christopher Heine in 2015 via Ad Age (Heine, 2015):

- 71 percent of 5,000 American businesses said mobile marketing is core to their business.

- 68 percent of 5,000 American businesses have integrated mobile into their larger marketing strategy.

- 58 percent of 5,000 American businesses have a dedicated mobile team.

- 73 percent of 5,000 American businesses think email is core to their business.

- 66 percent of 5,000 American businesses believe social media is core to their business.

- 66 percent of 5,000 American businesses have a dedicated social media team. 
- 56 percent of 5,000 American businesses said their corporate websites are their most effective digital technologies.

A survey produced by Pew in 2015 shows that at least $52 \%$ of American adults have logged onto at least one social media site every single day since registering, with Facebook taking up about $70 \%$ of that statistic. Although this data is hard to estimate Pew used methods that reached a low error margin, the Pew research surveyed 2,003 adults, including 1,597 Internet users, by cellphone and landline. It has a margin of error of plus or minus 2.5 percentage points (Goel, 2015). The one thing that this survey didn't track was the amount of time spent on each of these social media platforms. Even without the knowledge of how much time is spent on these sites it gives advertisers an opportunity to reach these people no matter how brief their visit is to a website or app. Social media is ever growing as a relevant option for advertisers to reach their audience. The way people use social media to communicate with brands and with other consumers has changed and it has created new opportunities to advertisers to reach their consumers in a more meaningful way.

\section{The Move Away From the Traditional Advertising Agency}

The traditional ad agency, or full service agency, has been structured in the same basic way for the past fifty years Advertisers have three basic pricing models:

The first is when agencies charge a percentage of total media sales, so if an advertising firm bought your brand $\$ 1,000,000$ worth of media spending, you would pay that advertising firm a negotiated fee of $10-20 \%(\$ 100,000$ to $\$ 200,000)$. 
The second way advertisers charge for their services is be negotiating a retainer with a company, which would cover all costs related to doing business. This is usually paid out on a monthly basis.

The third way is to calculate a total fee for the services that you are providing and to bill the company based on the services that were provided.

The main alternatives to these traditional firms are the smaller more specialized creative advertising agencies, and the media agencies whose main function is not the creative side of advertising. There is a constant and continuous cycle of small firms and spin off firms created by people who left larger firms (Nobles, 2017). The most common alternative to the traditional model is to create an in-house advertising agency, or to hire a less expensive and mostly digital advertising firm that has lower margins and keeps costs low with budget saving initiatives (Agrawal, 2016).

This new form of agency can often be more flexible to what different clients need. They can forge alliances between multiple disciplines, something that would require a larger firm to make cut backs or firings, even losing divisions of their shop. New digital firms have the ability to monitor customer information as quickly as they receive it, which can be a constant flow of information. This means more and more ads becoming very specific and very targeted to specific and sometimes a single consumer (Bruell, 2016). Marc Pritchard, the CMO of Procter \& Gamble stated, “...More agencies will rebundle capabilities such as creative and media, influencers and digital and production and shopper [marketing]' for individual brand needs. There will be dedicated client teams and a greater degree of open-sourcing of talent and capability" (Bruell, 2016). Mark Read 
of Wunderland and WPP Digital also states that agencies of the future will be more client and consumer-focused, with a smaller emphasis on channels of distribution (Bruell, 2016). Truly digital advertising firms know that in order to get people interacting with their brand they need to join in on the online conversations in a way that seems genuine (Epstein, 2015).

Technology is working to help smaller indie advertising agencies grow as well. Avi Dan, founder of Avidan Strategy stated that, "You can have a small agency somewhere in the Midwest and deliver an idea that through technology you could run in a hundred countries... You don't need that main office to run an efficient operation anymore." (Stilson, 2014).

The website smallbusiness.com described two pros and two cons of using the traditional all-in-one advertising agency. The pros were that it was a one-stop shop and had better integration into business models. The cons were that in large firms you often see less specialization in roles and a narrower view of business issues. This narrow view highlights the rigidity of large firms and the flexibility offered by smaller ones, with tradeoffs on both sides (Kokemuller, 2016). Since firms and consumers can be more nimble and specialized, they are expecting different things out of their advertising agency. There has always been evolution and change but the added power of the consumer could make this period of technology have a lasting effect on the advertising ecosystem. 


\section{Can Traditional Firms Make the Switch to Digital?}

While many advertising firms have gained access to tools that were only in our imagination a few decades ago, one aspect of the advertising ecosystem that has changed greatly is media buying. Certain aspects of media buying have become commoditized and require little to no human interaction to be successful. However many aspects of media remain just as creative and nuanced as thinking of a new tagline for an ad campaign. Increased visibility and accessibility has also increased how accountable these agencies need to be: not only do they now more than ever, and to prove that they have a purpose and help to drive profit, they must also be more aware than ever of what is happening in the world (Benady, 2016).

The lack of accountability has not only been a problem between advertisers and the public, but within the advertising ecosystem itself, with more and more advertisers only paying out if they have a measurable metric to mark their success. The dark side of viewability, or how much your advertisement was viewed, and accountability has occurred. Good produced a statistic last year saying that close to $60 \%$ of all the ads on Google were never seen. This false reporting has cost advertisers and the clients of advertisers across the world close to an estimated seven billion dollars. Many brands are paying for views that never happened.

Even when there is no fraud or bot accounts altering views, there is still much variability from one source to another about how much an ad was in fact seen or interacted with. It's now estimated that $97 \%$ of advertisers want a third party to gauge and verify how much their ad was interacted with (Mahlman, 2017). The most common 
ways to gauge how much your advertisement was interacted with are impressions; (every set of eyes that see your advertisement one time), or click-through rate, which is simply the number of times your advertisement was clicked on.

Recently, Facebook has been making strides in improving the transparency of their viewability for advertisers, especially in videos. Facebook made this statement: "Independent ad verification partnerships are critical to making sure advertisers trust their ad delivery data, so they can explore exactly how to drive value for their business in feedbased platforms." (Swant, April 2016).

Facebook has recently partnered with Moat, a third-party verifier for their views, after the considerable of negative attention they received on the perceived viewership fraud of the advertisements they hosted in 2016. This third-party verification is extremely important, given the fact that an estimated 85 cents from every dollar spent on digital advertising went directly to either Facebook or Google (Swant, April 2016). Mark Rabkin, head of Advertisement Engineering at Facebook, has introduced more advanced features to track video viewership that monitors audio and video streams separately to get a more accurate view of who finished the video and who listened to the whole thing as well. This will not only improve the accountability Facebook has for its video viewership, it will provide more unique and valuable insights into advertising campaigns being run on Facebook (Johnson, 2016).

With so many players in the game and so many small firms offering services that the large firms are only beginning to investigate, some new advertising agencies are reluctant to even call themselves advertising agencies. There have been a large number of 
“new-model, multidisciplinary marketing communication firms" popping up. In other words, these are ad firms that don't want to limit themselves, or don't want to make clients think that they are limited. Brad Jakeman states that “...agencies let ourselves get put into the box, and it's up to us to prove that we are more than just that" (Coffee, 2015).

It's not just small companies that are switching to digital firms, (or the new-model multidisciplinary marketing communication firms), to save money and increase their perceived productivity and effectiveness. Huge brands like Kellogg and Procter \& Gamble have realized that services previously provided by large agencies, like in-house buying technologies or large acquisitions, could all be done more effectively by with cutting out the middle-man, who just so happened to be the traditional advertising agency. Large brands set up their own media trading operations in order to keep their data more secure and to have more control over it. This new form of advertising agency is referred to mostly as the "ad-tech" firm, although there is no official name for the new type of business. Drew Kurth, CEO of digital marketing platforms at Publicis Groupe agency Razorfish say that this impending threat is not focused on profits, just in gaining market share. They are more willing to do work for free in order to gain a large name on their client list. Razorfish has had to cut fees. They now must charge for things like cloud-based soft ware in order to compete. To try and make up for it, Razorfish has to pitch to the client about why not to deal directly with these ad-tech programs, the time spent working with this technology will eat up so much time and energy in their company that they wont be saving as much as they think (Bruell \& Peterson, 2013). It's important to add that in 2016 Razorfish, who was bought by the larger advertising agency Publicis, was merged with another advertising agency to create a global advertising agency called 
SapientRazorfish. The new agency will have close to 12,000 employees, but they anticipate no layoffs with the merger (Stein, 2016).

\section{Are firms short Sighted?}

With the emergence of new technologies for marketing and advertising, including the technology stated earlier in this paper, many firms are under pressure to produce immediate results with measurable returns on investment. Marketing consultant Peter Field states that "The single greatest threat facing marketing at the moment is shorttermism: The dominant focus on this period's or quarter's sales". This short-term vision can lead to a myopic view of business and leave both advertisers and their client's blind to the future (Musi, 2017). Many economic studies have estimated that when you plan strategically with your advertising the benefits can be magnified by up to $14 \%$ over the course of a company's life. This is not to say that short-term goals and initiative are not important as well. However, as Peter Ducker states, "Long- term results cannot be achieved by piling short-term results on short-term results.”(Musi, 2017). However, 68\% of respondents in a survey conducted in 2015 stated that it's worth it to make short-term financial decisions and sacrifices for long-term development. This shows that long and short term need to co-exist for a business to be successful (Becker, 2015). A commonly used term in the advertising industry is the $60 / 40$ ratio, by which experts suggest keeping sixty percent of advertising spending on long term goals like brand building and only forty percent of advertising budget on short-term goals like sales activation (Musi, 2017).

With more consumers paying attention to multiple platforms including digital, print, and multiple others it's easy to think that no one is paying attention to long 
campaigns and that long-term goals and the traditional multiplier for advertising campaign effects is no longer in play. However, Nielsen recently duplicated a study it conducted in 1989, which tracked an ad's presence and effectiveness over a month (the shortest capstone for being defined as long-term,). The Neilson study found that contrary to popular belief, the sales lifts from the campaigns (Kellogg was used for this study) remained high at 1.8 to 4.5 times. For Kellogg specifically, the lift after the first month in sales was 3.5, which shows investing in long term ad goals is still a viable and profitable area for advertisers and companies to invest in (Neff, 2014). This demonstrates that lifts in sales are not only influenced by longer-term ad campaigns. Brands like Coca-Cola are just beginning to see returns from long-term campaigns like the "Share a Coke" campaign, which has just started to show a $2.5 \%$ increase in sales for Coke over the past year. This is significant due to the fact that Coca-Cola's main competitors like Pepsi have only seen declines in the past year, being unable to demonstrate the value of their product (McQuilkin, 2014).

With most mobile and digital technology favoring the short-term approach to advertising, traditional advertising firms who have often focused more on the long-term advertising goals are having a hard time competing. Although it remains imperative to keep long term goals in mind when doing any business transaction, including advertising. The fascination with immediate metrics like click-through rate and impressions are also driving more brands to have a short-term oriented focus 


\section{The Price Structure of Traditional Advertising Firms}

It's no secret that advertising can be expensive. A basic cable television thirty second television spot, can cost anywhere form $\$ 60,000$ to well over $\$ 1$ million, to write, shoot, cast, and produce. This doesn't include the other businesses that exist in the advertising ecosystem like the cost to pay actors, catering for the set, insurance, editing photos, etc. A print ad in a magazine can cost you more than $\$ 6,000$ dollars for a short run partial page in a medium range magazine. Popular magazines like People can cost up to $\$ 300,000$, although prices can vary immensely, how often or frequently an ad runs will also vastly affect the costs associated with ads (Severson, 2016).

Production and research can run upwards of $40 \%$ of the total advertising budget, and advertising takes up an average $20 \%$ of all marketing budgets. Some attribute this high cost level to something called "non-working" costs in an agency, which include fees for advertising agencies, talent, production and the market research behind creating and evaluating the ads and content. In one study, ad campaigns with a budget over $\$ 10$ million were found to spend an average $37 \%$ of their total budget on non-working media costs alone (Neff, 2015). When asked to identify what was driving these costs higher in a time where many agencies are cutting back to keep costs competitive, Chris Bolman, Percolate's Director of Growth stated that emerging media formats were expensive and agencies were having to spend more on briefing, planning, media evaluations, and employee talent costs (Neff, 2015). This time spent planning while considered a loss from the point of view of brands, may spell success in the long run

Many sound bites or snippets about "non-working" costs are circulating around Wall Street right now, and many large firms are working hard to reduce these costs. 
There is no specific definition for these costs and sometimes what's included in them is vital for a company to thrive. Tom Finneran, executive VP-agency management services at the American Association of Advertising Agencies, made this statement about nonworking costs and definition, “...they inadvertently include earned media, owned media, web content, web videos, social media curation and targeted message executions that are not sourced from paid media publishers in the non-working category of expenses. They may also include agency fees, production, research and other 'non-paid' media as nonworking."(Finneran, 2016).

What many companies who want to cut spending on non-working costs don't consider is not only how much they are spending on getting their message out but also the quality of that message. They take owned and earned media for granted, their definition implies that only working costs actually add value to their firm and non-working costs don't add anything, which can sometimes be the exact opposite of the truth (Finneran, 2016).

Michael Farmer, CEO of Farmer \& Company has identified three major things agencies are doing wrong that are driving up costs and essentially putting themselves out of business: The first is that they have an outdated compensation model, which hasn't been updated in decades.

The second is that Agencies are creating more work and deliverables than ever before but the metrics to measure their success or how an advertisement was received have not caught up. 
The third is that agencies are facing an existential crisis, without the proper metrics or proof to show that their services actually help drive sales they are unsure if they are a necessary costs (Beasley, 2016).

One major warning that larger firms should be looking at is Procter \& Gamble, a huge traditional advertising client that has decided to cut costs and has chosen advertising as the first place it wants to cut. Procter \& Gamble plans to cut $\$ 1$ billion out of their media budget and $\$ 500$ million in agency costs (Neff, 2017). Unilever, a huge competitor of Proctor \& Gamble has decided to take a very similar approach. They plan to cut agency spending and non-working costs by $\$ 470$ million dollars this year. Unilever plans move their spending to digital, with the percentage that will be switched to digital varying from client to client. Where the non-working costs are lower and things like production costs and agency fees, these forms of advertising have a much smaller margin as compared to more traditional forms of advertising. Since 2010, Unilever estimates that they have cut the amount of their advertising budget that goes towards non-working costs from $32 \%$ to $20 \%$ (Neff, 2013).

With the traditional business model of advertising being challenged, many clients who would normally seek out the traditional advertising firm are straying. Brad Jakeman, the president of PepsiCo stated that " the ad agency model is broken, that large agency networks are dinosaurs and that agency retainer relationships are disappearing as clients are being way more promiscuous with their agencies than they ever have" (Sharp, 2015). This promiscuity among clients, and the high saturation of independent advertising startups has been deemed the indie-agency boom. As stated previously many clients are no longer in need of the traditional advertising agency and if they choose to employ one, 
they feel they are just as well off getting a firm to do their media buying. The advertising world has been experiencing huge amounts of turnover across a multitude of agencies, meaning that even if a client chooses to get an expensive adverting firm on their retainer by the time the year is out they could be working with all new people (Sharp, 2015).

Large brands and companies who often need more than one agency to keep their advertising needs satisfied have started to not name a single agency on record and have started to assign different projects to multiple different agencies, giving out small chunks of a campaign or a product launch instead of giving it all to one firm (Stilson, 2014). Brands are realizing that with evolving technology there is no longer as strong of a need to outsource their work to advertising firms. This is a trend that has come and gone in the advertising world, but this time with the new technology, it could be more permanent.

\section{High Turnover in the Advertising Ecosystem}

Many staff members at larger advertising are breaking off to do freelance work or are beginning to create their own agency. Turnover rate in advertising agencies is estimated to have grown by $10 \%$ from 2015 to 2016 (Richards, 2016). Last year alone twenty-six ad agencies joined the American Association of Advertising Agencies, a trade

association for Advertising Agencies, that claims to produce upwards of eighty percent of all advertising work put out Nationwide (Admin, 2017) nationwide there are estimated to be close to 120,000 advertising agencies but only around $8 \%$ of them get verified by the 4A's. This shows that these smaller firms that are starting up are more than just a few people in garage, they are here to compete on a larger scale.

However many "indie”, or small and untraditional, advertising agencies are unable to sustain themselves (Stilson, 2014). Even large firms with the resources to 
maintain larger teams within agencies are having trouble with the high turnover rate in the industry. The instability is causing not only employees to worry but clients as well. One of the grounding principals in the advertising world is one cause of the high turnover rate, and that is the fact that new business is the lifeblood of any agency. Robby Berthume of Bull \&Beard states that when a new client comes on the account tends to be over staffed, and if that clients decided to go to a different firm that leaves the agency with too many employees and not enough clients. A lack of independence and a tendency to prioritize business savvy employees rather than creative ones can cause unrest in the industry, causing slow workflow and low morale (Council, 2016).

Paul Gumbinner, president of Gumbinner Co. and a 20-year advertising veteran, stated that the number one thing driving this high turnover rate is lack of employee recognition. In a large firm an employee is unlikely to get a pat on the back from the boss, but employee level recognition is rare in even a small firm. Many people in advertising are also working 60-80 hour workweeks, and employees are starting to realize that they can work somewhere else and get paid more to do less work (Gumbinner, 2010). This ties in with a survey conducted by Linked-in, that states the reason $45 \%$ of people gave for leaving a firm was that they felt there was no room for advancement or promotion, $50 \%$ said they wanted more challenging work from agencies, and $46 \%$ of people said they were unhappy with agency leadership (Richards, 2016).

All the employee distress is causing record breaking low morale in advertising agencies, with a study conducted in 2015 stating that $34 \%$ of employees in the firms they went to and interviewed said that their morale was either low or dangerously low (Fromowitz, 2017). Employee loyalty and morale is incredibly important. Another study 
found that when a company who made improving productivity their main goal invested $10 \%$ of their budget on capital improvements they saw a $3.9 \%$ increase in productivity. When firms spent the same amount of money on their employees they saw a $8.5 \%$ rise in productivity, which shows that having loyal and happy employees is a good investment (Keiningham \& Aksoy, 2017).

A study conducted in 2015 that interviewed 500 advertising executives across the country came to this conclusion about company culture: Culture has more influence over whether or not a business relationship with clients will be long lasting than actual results. $60 \%$ of the respondents in the study stated that knowing what a company stands for is more important than how innovative that company is, and $81 \%$ of respondents stated that the more successful companies are at building a bridge between what you believe as a company and what you do influences whether or not that company can build a lasting relationship (Becker, 2015). One common theme for firms who choose the short-term approach is that they tend to lose the customer-focused business model and focus more on the short-term bottom line, which can increase sales in the short run but has not been as proven as successful in the long-term (Suther, 2012).

Having high employee engagement, or having employees who actively believe in and participate in the business, and who choose to go above and beyond for the company, can be the difference between success and failure. It's estimated that low employee engagement can be costing the business world billions of dollars a year due to low productivity, accidents, theft, and high turnover. Companies that actively invest in employee engagement, can on average can see more than twice the growth in revenue, as companies who do not actively work on employee engagement (Follini, 2016). 
A major trend in business but also in advertising is an emphasis on running your business in a sustainable, ethical, and socially responsible way. A study found that $79 \%$ of graduates entering the business world consider a company's corporate social responsibility when choosing a place to work. A company with low morals or ethics can be costing you and your business the young creators of the future, and can be costing you good employees (Follini, 2016). 70\% of millennials say they would spend more money on a brand that they think is supporting causes they stand behind. Corporate Social Responsibility (CSR) is the commonly accepted phrase for the idea that the best companies realize and act on their long-term responsibility to society. Large brands like Nike and Google have started to integrate CSR into their overall business strategy and ad firms like 72 and Sunny have followed suit and started their own initiatives to attract business, realizing that to attract CSR-oriented clients, they themselves must adhere to CSR standards (Richards, 2015). Kirk Souder, co-founder of Enso stated that, "Brands started saying we can't continue to have this approach to social responsibility ... doing something in the margins. We have to embed it deeply into the business". This concept of CSR must be genuine or customers and clients will see right through it. It has to be integrated into the business in a way that is not only reflected to the public, but is reflected among every person who works at that firm (Richards, 2015).

A survey taken of over 10,000 people aged 18 to 28 found that $73 \%$ of respondent think that companies have a moral responsibility to help society in some way, and $75 \%$ of people who believed that also believed that they should do it in a way that doesn't hurt the environment. Four ways to make your CSR more meaningful and not just a ploy for the millennial vote is to put your brand at the center and highlight the positive leaders in 
your industry and firm. Having a call to action for your consumers and creating a culture around your CSR are also vital in creating lasting change and profit (Walker, 2016).

Authenticity has been proven to be important not only for employees but consumers as well, and having an authentic story behind your CSR can help to drive its success, utilizing people who are experts in the field and consulting with them before making a move can save your company heartache and money when moving forward with certain CSR issues (Follini, 2016).

\section{Agencies Don't Know if They Matter Anymore}

Metric fraud, or the false reporting of how well an advertisement is performing, has become a hot topic among advertisers. Turn and Amobee conducted a survey of 200 advertising executives, and found that people under thirty are far less likely to be worried about metric fraud. This is partially because younger generations grew up with a natural distrust for the Internet and has become more skeptical (Swant, 2017).

Advertisers and clients both know that metrics like click-through rate, (which is defined as the ratio between people who click on your advertisement and people who saw your advertisement [Adwords, 2017]), and impressions are not very accurate and are sometimes misleading. The current Media Rating Council standard for impressions is that if someone looked at your online advertisement for 1-2 seconds that advertising agencies are allowed to count that as an impression and charge brands and customers for it (Heine, February 2015). Even so these metrics continue to show up on almost every single campaign report put out today. Rachel Herskovitz, the global media manager at American Express has herself expressed that the standards set around impressions, or every set of eyes that sees your advertisement one time is not realistic. Many advertising agencies are 
considering a switch to third party verifiers to be able to guarantee accuracy for their clients. One-statistic claims that close to $60 \%$ of clients would consider switching away from an agency that didn't have a third party verifier for their metrics. As the familiar adage goes, not everything that counts can be counted and not everything that can be counted counts (Minoff, 216).

With a rising number of young people being exposed to ads it is no surprise that brands like Netflix are noticing that about half of all of their content being viewed is on a small screen other than a television, and the people who are watching on them are only viewing content for round 10 minutes on average. Erin McPherson, the Maker Studio's chief content officer has stated that millennials' won't be reached with traditional advertising. It's not that millennials are going against brands, but they are against the inauthentic feeling of advertising, feeling that "The new authority is authenticity". This would mean a sizeable shift in the way advertising has been done for many firms, but the over-the-top fake ads are going extinct (Castillo, 2015). For there to be a place for traditional advertising in the future, they need to focus on creating authentic connections with consumers and get back to the roots of communication.

\section{What Metrics are there and how Reliable Are They}

When anyone chooses to partner with an advertising firm, they are hoping to get a high return on their investment or "ROI". Today it's getting harder to track your advertisement had an effect, and if it did, to what extent. $61 \%$ of social media professionals surveyed stated that tracking and calculating ROI was their greatest challenge (Morrison, June 2016). Previously advertisers have relied on abstract concepts like engagement rate, impressions, or page visits to track the success of an online 
campaign. However these are not always the most reliable. In fact, marketers and advertisers have only a vague idea of how many people saw their ad. With online fraud, dark web sharing, and a fragmented audience who might view the ad on multiple platforms but get counted as unique impressions, it is almost impossible to see who you reached (Morrison, April 2016). This is also making harder to tell which form of advertising was effective: If a customer saw three ads you produced, which one was the one that pushed them to the final purchase? This is summed up in a quote from John Wanamaker, “...half the money I spend on advertising is wasted; the trouble is I don't know which half" (Chait, 2015).

A survey conducted among 350 social media professionals shows that $56 \%$ of marketers are still using engagement, or impression-based metrics, as their main metric for measuring success, while only $20.7 \%$ focus on conversations had on their page (Morrison, June 2016).

A survey of 154 advertisers found that $90 \%$ of them were not fully confident in metrics given for online ad campaigns, and they had no idea if their advertisements were meeting industry viewability standards (Neff, November 2015).97\% of respondents in the same survey they would like some sort of third party verification for their online metrics, but Facebook and Google, who comprise $60 \%$ of all dollars spent online for advertisers are holdout who do not have such tools in place. YouTube has announced that it will allow third party verification, and with a growing number of verified third party firms, (currently around 20), there is no shortage of firms to choose from (Neff, November 2015). 
Adam Snyder, the managing partner of ALS Impact defines impression as "the number of people who potentially, maybe, for some brief moment could have been exposed to a piece of content". While not a completely obsolete way of measuring the success of an online campaign there are other metrics that should be considered that can be more accurate in assessing the success of a campaign. Snyder states that his two top metrics for tracking success are first, the number of times an article or an image gets shared on different social media platforms, and second tracking the negative reviews or sentiments form online comments, and using these tools to not only asses the complete reach that a campaign could have had but tacking the quality of that reach (Snyder, 2015).

\section{Conclusion/ Next Steps}

After Looking at over 55 sources from Experts in the advertising, ad tech world, and the business world, I have laid out a very current landscape of where the advertising world is today. With all but two of my sources being les than five years old I have attempted to create a snapshot of where the advertising world is at the current moment. My next steps if I were to continue to do work on this topic would to get my IRB certification and begin to do interviews with people who either work in the advertising field or people who will be entering it soon. Because I purposely did not include any scholarly sources another next step would be to conduct interviews with professors and start to gather scholarly articles that have been published within the past five years. These interviews would be very helpful in gaining insight into the current and possibly future state of advertising, Ad Age and Adweek have offered a similar view, most of the articles not only incorporate data from surveys and studies conducted, but they also include some 
form of the authors opinions, which has allowed me to create an accurate view of the ecosystem of the advertising agency. 


\section{Works Cited}

Adwords. "Clickthrough Rate (CTR): Definition - AdWords Help." Google. Google, 2017. Web. 25 May 2017.

Agrawal, AJ. "Are Traditional Ad Agencies Bad for Business?" The Huffington Post. TheHuffingtonPost.com, 28 June 2016. Web. 02 May 2017.

Becker, Christoph. "Corporate Culture Has Become the Most Powerful Force in Forging Partnerships." - Adweek. Adweek, 29 Nov. 2015. Web. 11 May 2017.

Beasley, Keenan. "How Agencies Are Putting Themselves Out Of Business And What We Should Do About It." Forbes. Forbes Magazine, 08 Feb. 2016. Web. 02 May 2017.

Benady, David. "How Will the Marketing Agency Digital Revolution Be Advertised?" The Guardian. Guardian News and Media, 13 June 2016. Web. 02 May 2017.

Bennett, Shea. "How Social Media Helps Small Businesses Grow [INFOGRAPHIC]." - Adweek. Adweek, 16 Dec. 2013. Web. 25 Apr. 2017.

Biery, Mary Ellen. "The State Of U.S. Small Businesses Entering 2016." Forbes. Forbes Magazine, 18 Jan. 2016. Web. 11 May 2017.

Bruell., Alexandra. "The Ad Agency of the Future Is Coming. Are You Ready?" Ad Age. N.p., 02 May 2016. Web. 02 May 2017.

Bruell, Alexandra, and Tim Peterson. "Adland's Battle Royale: Agencies Defend Turf As Ad Tech Moves In On Clients." Ad Age. N.p., 13 Oct. 2013. Web. 09 May 2017.

Castillo, Michelle. "How to Advertise to the Millennial Who Hates Advertising." Adweek. Adweek, 9 Feb. 2015. Web. 22 May 2017.

Chait, Gerald. "'Half the Money I Spend on Advertising Is Wasted; the Trouble Is I Don't Know Which Half."' B2b Marketing. N.p., 8 Mar. 2015. Web. 08 June 2017. 
Cleveland., Bart. "New Biz Should Be Business as Usual." Ad Age. N.p., 03 Mar. 2006. Web. 26 Apr. 2017.

Coffee, Patrick. "Why Today's Ad Agencies Are Reluctant to CallThemselves' AdAgencies'."Adweek. Adweek, 10 Nov. 2015. Web. 03 May 2017.

Council, Forbes Agency. "Nine Ways For Your Agency To Combat A High Turnover Rate."Forbes. Forbes Magazine, 19 Oct. 2016. Web. 09 May 2017.

Epstein, Stacey. "Why the Traditional Ad Agency Is a Dying Breed." Mashable. Mashable, 30 July 2015. Web. 02 May 2017.

Farley, Claire. "Is 2016 the Year of Talent for Digital Marketing?" Ad Age. N.p., 21 July 2016. Web. 27 Apr. 2017.

Finneran, Tom. "Dispelling the Myth of Working vs. Non-Working Marketing Spending." Ad Age. N.p., 07 Jan. 2016. Web. 09 May 2017.

Follini, CJ. "How the Power of Employee Engagement Will Boost Your Business." Adweek.Adweek, 27 Sept. 2016. Web. 11 May 2017.

Fromowitz, Mike. "The Sad State of Advertising Agency Morale." Campaign Asia. N.p., 3 Jan. 2017.Web. 09 May 2017.

Gianatasio, Dave. "How Millennials Are Changing the Way Ad Agencies Work." Adweek. Adweek, 30 Mar. 2015. Web. 27 Apr. 2017.

Goel, Vindu. "Americans Use More Online Social Networks." Nytimes. N.p., 9 Jan. 2015. Web. 2 May 2017.

Guest. "The Biggest Problem With Micro-Influencers (and How to Solve It)." - Adweek. Adweek, 17 May 2016. Web. 25 Apr. 2017.

Gumbinner., Paul S. "Eight Ways to Lower Agency Employee Turnover." Ad Age. N.p., 
01 Mar. 2010.Web. 09 May 2017.

Heine, Christopher, and Marty Swant. "What the Proliferation of Fake News on Google and

Facebook Means for Advertisers." Adweek. Adweek, 16 Nov. 2016. Web. 27 Apr. 2017.

Heine, Christopher. "70\% of Marketers Will Spend More on Social Media Ads This

Year."Adweek. Adweek, 12 Jan. 2015. Web. 27 Apr. 2017.

Heine, Chris. "What Counts as an Online Ad View? A Standard Is Nearing, but the Fight's Not

Over." - Adweek. Adweek, 26 Feb. 2015. Web. 25 May 2017.

Hendricks, Drew. "How Mobile Technology Has Revolutionized Small Business." Tech.Co.

N.p., 24 Oct. 2014. Web. 25 Apr. 2017.

Johnson, Lauren. "Facebook Increases Transparency By Updating Video and Third-Party

Viewability Metrics." - Adweek. Adweek, 16 Nov. 2016. Web. 24 May 2017.

Kokemuller, Neil. "Advantages and Disadvantages of Full Service Advertising

Agencies."Chron.com. Chron.com, 26 Oct. 2016. Web. 11 May 2017.

Keiningham, Timothy, and Lerzan Aksoy. "Why Managers Should Care About

Employee Loyalty IMonster.com." Monster Hiring Resource Center. N.p., 2017.

Web. 09 May 2017.

Mahlman., Tim. "Accountability and Trust in the Ad Ecosystem: How Platforms Can Help." Ad Age. N.p., 03 Mar. 2017. Web. 02 May 2017.

McMains, Andrew. "Small Businesses Are Slow to the Digital Party." - Adweek. Adweek, 19 Mar. 2013. Web. 25 Apr. 2017.

McQuilkin, Toni. "'Share a Coke' Campaign Grows Sales For First Time in 10 Years, WSJ

Reports." - Adweek. Adweek, 26 Sept. 2014. Web. 24 May 2017.

Minoff, Matt. "Why It's Time for Marketers to Rethink Metrics and Performance 
Indicators." -Adweek. Adweek, 20 May 2016. Web. 09 May 2017.

Morrison, Kimberlee. "How Mobile Apps Impact Consumer Shopping Habits [Infographic]." Adweek. Adweek, 3 Oct. 2014. Web. 25 Apr. 2017.

Morrison, Kimberlee. "The Growth of Social Media: From Passing Trend to International Obsession." Ad Age. Ad Age, 27 Jan. 2014. Web. 27 Apr. 2017.

Morrison, Kimberlee. "Are Social Marketers Focused on the Wrong Metrics?" - Adweek. Adweek, 5 Apr. 2016. Web. 11 May 2017.

Musi, George. "The Downside of Digital's Explosive Growth? Too Many Marketers Are Failing to Think Long-Term." Adweek. Adweek, 22 Mar. 2017. Web. 09 May 2017.

Neff, Jack. "P\&G Will Cut \$2 Billion in Marketing but Spend Some Back to Become 'Irresistible'." Ad Age. N.p., 26 Apr. 2017. Web. 09 May 2017.

Neff, Jack. "Unilever Plans To Cut 800 Marketers As It Slashes Agency Fees, Products." Ad Age. N.p., 05 Dec. 2013. Web. 09 May 2017.

Neff., Jack. "Study: Long-Term Sales Lift From Advertising Stronger Than Ever." Ad Age. N.p., 10 June 2014. Web. 09 May 2017.

Neff., Jack. "Study: Agency and Production Costs Keep Rising Despite Efforts to Cut Them."Ad Age. N.p., 17 Dec. 2015. Web. 02 May 2017.

Neff., Jack. "ANA: Almost All Marketers Want Third-Party Verification of Digital Ad Views." Ad Age. N.p., 23 Nov. 2015. Web. 11 May 2017.

Nobles, Chuck. Portland State University. In-person. 9 June 2017. 13 June 2017.

O'Leary, Noreen. "Agency Cuts and Consolidation Are Likely to Follow Kraft Heinz Merger."Adweek. Adweek, 25 Mar. 2015. Web. 27 Apr. 2017.

Richards, Katie. "How Agencies Are Meeting Millennials' Demand for Socially 
Responsible Marketing." - Adweek. Adweek, 15 Dec. 2015. Web. 11 May 2017.

Richards, Katie. "Why So Many People Leave Advertising." - Adweek. Adweek, 22 Mar. 2016. Web.09 May 2017.

Roper, Tim. "How the Hyphen Is Shaping the Future of Advertising." - Adweek. Adweek, 24 Oct. 2016. Web. 22 May 2017.

Sammis., Kristy. "Go Small or Go Home: Despite Criticism, Microinfluencers Are Crushing It." Ad Age. Ad Age, 03 Apr. 2017. Web. 25 Apr. 2017.

Severson, Dana. "The Average Cost of National Advertising Campaigns." Back. Azcentral.com, 29 Sept. 2016. Web. 02 May 2017.

Sharp, Michael. "After a 'Promiscuous' 2015, Do Agencies and Brands Need Their Own Tinder?" - Adweek. Adweek, 17 Dec. 2015. Web. 03 May 2017.

"Small Business Trends | The U.S. Small Business Administration." Small Business Administration. N.p., n.d. Web. 25 Apr. 2017.

Snyder., Adam. "Marketers, It's Time to Ditch the Impression Metric." Ad Age. N.p., 21

Dec. 2015. Web. 17 May 2017./.latest_citation_text

Stein, Lindsay. "Publicis Merges Digital Shops SapientNitro and Razorfish, Creating SapientRazorfish." Ad Age. N.p., 17 Nov. 2016. Web. 08 June 2017.

Stilson, Janet. "Can Indie Ad Agencies Thrive in the Merger Era?" - Adweek. Adweek, 20 May 2014. Web. 03 May 2017.

Suther., Tim. "Long-term Success vs. Short-term Gratification: A Study of Two Companies."Ad Age.N.p., 03 Sept. 2012. Web. 11 May 2017.

Swant, Marty. "Survey Shows Older and Younger Ad Execs Care About Different Digital Metrics." -Adweek. Adweek, 3 May 2017. Web. 09 May 2017. 
Swant, Marty. "Facebook Partners With 3 Companies to Improve Its Verification of Ad Metrics." - Adweek. Adweek, 19 Apr. 2016. Web. 24 May 2017.

"U.S. Population with a Social Media Profile 2017." Statista. Edison Research; Triton Digital, n.d. Web. 25 Apr. 2017.

Walker, Matt. "4 Ways Agencies Can Add Meaning to Corporate Social Responsibility Programs." -Adweek. Adweek, 30 Aug. 2016. Web. 11 May 2017. 